\title{
COMPARISON OF HAEMODYNAMIC EFFECTS OF ETOMIDATE AND PROPOFOL PLUS MEPHENTERMINE FOR INDUCTION IN GENERAL ANAESTHESIA IN RESUSCITATED PATIENTS FOLLOWING HYPOVOLAEMIC SHOCK
}

\author{
Swaraj Sonowal1 1 Deba Gopal Pathak², Debashish Mondal ${ }^{3}$, Bhaskarjyoti Deka ${ }^{4}$ \\ 1 Post Graduate Trainee, Department of Anaesthesiology, Silchar Medical College. \\ 2 Professor and HOD, Department of Anaesthesiology, Silchar Medical College. \\ ${ }^{3}$ Post Graduate Trainee, Department of Anaesthesiology, Silchar Medical College. \\ 4 Post Graduate Trainee, Department of Anaesthesiology, Silchar Medical College. \\ 5 Post Graduate Trainee, Department of Anaesthesiology, Silchar Medical College.
}

\begin{tabular}{l} 
ABSTRACT \\
\hline BACKGROUND \\
The process of induction with an intravenous induction agent is one of the most crucial part while administering general \\
anaesthesia to a patient. The risks associated with IV induction such as sudden hypotension, arrthymias, and cardiovascular collapse \\
are life threatening complications following injection of induction agent in haemodynamically unstable patients. It is desirable to use \\
a safe agent with fewer adverse effect for this purpose.
\end{tabular}

\section{OBJECTIVE}

The present study was conducted to compare the haemodynamic effects of etomidate and propofol with mephentermine for induction of general anaesthesia in resuscitated patients following hypovolaemic shock.

\section{METHODS}

The study was conducted in 30 resuscitated patients following hypovolaemic shock put for emergency surgery foll owing initial resuscitation was allocated in two groups - Group A (Received injection etomidate $0.3 \mathrm{mg} / \mathrm{kg}$ body weight), Group B (Received injection propofol 1\%@ $2 \mathrm{mg} / \mathrm{kg}$ body weight with $6 \mathrm{mg}$ injection mephentermine sulphate 5 min before administration of propofol).

\section{RESULTS}

The results were analysed using appropriate statistical test. The data compiled were analysed with GraphPad InStat 3 statistical software. For qualitative data, chi-square test was used. Quantitative data were analysed using student t-test. P value $<0.05$ was considered to be significant and $P$ value $<0.001$ was considered highly significant and $P$ value $>0.05$ considered to be insignificant. Demographic variables (Age,sex , weight in $\mathrm{kg}$ ) were comparable between the two groups with the P value remaining insignifanct when comparison done between two groups; age in yrs., sex (M:F), weight in $\mathrm{kg}$, all p value nonsignificant, patients vital parameters (Heart rate, systolic BP, diastolic BP, MAP, Sp02 all found to be insignificant. When side effects are compared between two groups (Apnea on induction not significant, 50\% patient in propofol group complained of pain on injection while it is $40 \%$ only in etomidate group not significant).

\section{CONCLUSION}

As per study results obtained, we came to the conclusion that no significant difference is seen between the two study groups, group A and group B with respect to haemodynamic stability and side effects of drug used. Therefore, we suggest that both inj. etomidate and inj. propofol plus mephentermine combination can be used as IV induction agent in resuscitated hypovolaemic patient.

\section{KEYWORDS}

Hypovolaemic Shock, Induction, General Anaesthesia, Etomidate, Propofol, Mephentermine.

HOW TO CITE THIS ARTICLE: Sonowal S, Pathak DG, Mondal D, et al. Comparison of haemodynamic effects of etomidate and propofol plus mephentermine for induction in general anaesthesia in resuscitated patients following hypovolaemic shock. J. Evolution Med. Dent. Sci. 2016;5(63):4443-4447, DOI: 10.14260/jemds/2016/1014

Financial or Other, Competing Interest: None.

Submission 19-06-2016, Peer Review 24-07-2016,

Acceptance 30-07-2016, Published 06-08-2016.

Corresponding Author:

Swaraj Sonowal,

Department of Anaesthesiology,

Silchar Medical College,

Ghungoor, Silchar-788014,

Cachar, Assam.

E-mail: swarajsonowal@gmail.com

DOI: $10.14260 /$ jemds/2016/1014

\section{INTRODUCTION}

Circulatory shock, known as shock, is a life-threatening clinical condition characterised by low blood perfusion to tissues leading to inadequate tissue function and cellular injury. ${ }^{1}$ The signs of circulatory shock are rapid heart rate, decreased blood pressure, and signs of poor end-organ perfusion like low urine output, confusion, or loss of consciousness. Types of shock are hypovolaemic, cardiogenic, septic, and neurogenic shock. Shock progresses itself by positive feedback mechanism i.e. decrease in blood supply to tissues leads to cellular damage, which in turn leads to inflammation of tissues resulting in 
inhibition of perfusion further. ${ }^{2}$ Therefore, immediate treatment of shock is very critical for the survival of sufferer.

Therefore, it is quite challenging for the anaesthesiologists in conducting anaesthesia especially during induction on those who are prone for haemodynamic crisis due to haemodynamic instability. The anaesthesiologist must have a precise anaesthetic plan based on thorough evaluation of these haemodynamically compromised patients. Primary circulatory status of patients including mental status, blood pressure, urine output, and skin perfusion as well as more active assessment methods of intravascular volume status and cardiovascular function are of prime importance. In order to haemodynamically stabilise shock patients, adequate fluid resuscitation must be done prior to induction. Most anaesthetic induction agents causes lowering of blood pressure. Drug-like etomidate has a definite role in this situation, which has less cardiovascular instability effects than propofol and thiopental, but it has the potential for adrenocortical suppression, which may have deleterious effect on the patient.

\section{METHODS}

This study was conducted under the Department of Anaesthesiology and Critical Care, Silchar Medical College and Hospital, Silchar after approval from the hospital ethics committee and after obtaining patient's wherever possible and attendant's informed consent. The study was carried out on 30 resuscitated patients following hypovolaemic shock put for emergency surgery.

\section{Inclusion Criteria}

- Patients of both sexes between the age group 20 to 50 years.

- Patients posted for emergency surgery.

\section{Exclusion Criteria}

- Patient with head injury.

- Patients with egg allergy.

\section{Plan of Study}

The patients were allocated into two groups of 15 each.

\section{Group A}

Induction done with etomidate $(0.3 \mathrm{mg} / \mathrm{kg}$ body weight $)$ dose according to ideal body weight.

\section{Group B}

Induction done with propofol $1 \%$ ( $2 \mathrm{mg} / \mathrm{kg}$ body weight) with $6 \mathrm{mg}$ mephentermine $5 \mathrm{~min}$ before administration of propofol.

After detailed preoperative history from patient whoever can and from reliable attendants, physical examination was done. On arrival in the operation theatre, patient's pulse rate, systolic, diastolic, mean blood pressure, and $\mathrm{SpO}_{2}$ were recorded and ECG probe connected. Resuscitation done with intravenous fluids (Crystalloids, colloid, and blood) along with vasopressors whenever required. The resuscitation was continued till the systolic blood pressure becomes above 100 $\mathrm{mmHg}$ or mean arterial pressure above $65 \mathrm{mmHg}$ or haematocrit more than $30 \%$ or urine output greater than 0.5 $\mathrm{mL} / \mathrm{kg} / \mathrm{hr}$.
Glycopyrrolate $0.2 \mathrm{mg}$, midazolam $0.02 \mathrm{mg} / \mathrm{kg}$, and fentanyl $3 \mu \mathrm{g} / \mathrm{kg}$ IV were injected followed by an induction dose of either etomidate $0.3 \mathrm{mg} / \mathrm{kg}$ or propofol $1 \%$ with $6 \mathrm{mg}$ mephentermine. Trachea was intubated with appropriate size of endotracheal tube after $3 \mathrm{~min}$ of intubating dose of vecuronium $(0.1 \mathrm{mg} / \mathrm{kg})$ IV. Endotracheal tube was secured after confirming correct position and positive pressure ventilation was initiated. Anaesthesia was maintained with oxygen and nitrous oxide (33:67) and isoflurane along with intermittent doses of vecuronium as required throughout the surgery. Heart rate, noninvasive blood pressure, oxygen saturation by pulse oximetry were recorded just before intubation and at 5 minutes, 10 minutes, and 15 minutes.

\section{RESULTS}

The study was conducted over a period of six months duration. A total number of 30 patients allocated into two groups of 15 each Group A and Group B respectively.

Group A received inj. etomidate $0.3 \mathrm{mg} / \mathrm{kg}$ body weight as induction agent.

Group B received inj. propofol $2 \mathrm{mg} / \mathrm{kg}$ body weight along with inj. mephentermine sulphate $6 \mathrm{mg} 5 \mathrm{mins}$ prior to administration of propofol.

There were no statistical differences according to demographic data (Age, sex, weight). P-value for age-0.5369, sex-0.9999, weight-0.6897 being nonsignificant ( $p>0.05$ ).

There were no statistical differences between two groups in respect of vital parameters, which were monitored before intubation and at $1 \mathrm{~min}, 5 \mathrm{~min}, 10 \mathrm{~min}$, and $15 \mathrm{mins}$ respectively. The p-values for heart rate-0.8154, systolic BP0.5744, diastolic BP-0.5529, MAP-0.5689, $\mathrm{SpO}_{2}-0.2403$, which are all being nonsignificant.

Regarding side effects, the incidence of apnoea was similar in both groups. ( $p>0.05)$. Myoclonic movements were seen only in etomidate group. ( $p>0.05$ ). Fifty percent of patients receiving propofol complained of pain injection while only four percent in etomidate group. $(\mathrm{p}>0.05)$.

\begin{tabular}{|c|c|c|}
\hline \multirow[t]{2}{*}{ Study Groups } & \multicolumn{2}{|c|}{ Apnoea on Induction } \\
\hline & Yes & no \\
\hline Group A & $5(33 \%)$ & $10(67 \%)$ \\
\hline Group B & $9(60 \%)$ & $6(40 \%)$ \\
\hline
\end{tabular}

$P$ value $=>0.9999$

$P$ value summary $=$ ns (not significant)

\section{Incidence and Grading of Pain on Injection}

\begin{tabular}{|c|c|c|}
\hline & Pain on Injection & P Value \\
\hline Group A & Grade 0 grade 1 grade 2 & 0.9252 \\
Group B & 960 & Not significant. \\
\hline
\end{tabular}

Grade 0-no pain, grade 1-verbal complaint of pain, grade 2withdrawal of arm, grade 3-both verbal complaint and withdrawal patient characteristics (mean \pm sd). 


\begin{tabular}{|c|c|c|c|c|}
\hline Patients Characteristics & Group A (N=15) & Group B (N=15) & P-Value & Result \\
\hline Age (years) & $32.86 \pm 8.36$ & $31.2 \pm 6.05$ & 0.5369 & Not significant \\
Sex (M:F) & $7: 8$ & $10: 5$ & $>0.9999$ & Not significant \\
Weight(kg) & $52.6 \pm 9.37$ & $54 \pm 9.63$ & 0.6897 & Not significant \\
\hline
\end{tabular}

\section{Parameters before Admission}

\begin{tabular}{|c|c|c|c|c|}
\hline Vital Parameters & \multicolumn{2}{|c|}{ Group A (N=15) } & \multicolumn{2}{c|}{ Group B (N=15) } \\
\hline & Mean (avg.) & SD (avg.) & Mean (avg.) & Sd (avg.) \\
\hline heart rate & 138.6 & 16.6 & 121.5 & 15.8 \\
systolic BP & 86.7 & 7.13 & 79.9 & 7.53 \\
diastolic BP & 44.7 & 6.10 & 49.02 & 6.89 \\
\hline
\end{tabular}

\section{Type of Surgeries}

\begin{tabular}{|c|c|c|c|c|}
\hline Surgery Performed & Group A & $\%$ & Group B & $\%$ \\
\hline Exploratory laparotomy for ruptured ectopic pregnancy & 8 & $53.3 \%$ & 5 & 33.3 \\
\hline Exploratory laparotomy for uterine rupture & 3 & 20 & 4 & 26.6 \\
\hline Exploratory laparotomy for haemoperitoneum & 2 & 13.3 & 3 & 20 \\
\hline Amputation for crush limb injury & 2 & 13.3 & 3 & 20 \\
\hline
\end{tabular}

\section{Patient's vital Parameters}

\begin{tabular}{|c|c|c|c|c|}
\hline Group A & Before Intubation (mean \pm SD) & $\mathbf{5}$ min & $\mathbf{1 0}$ min & $\mathbf{1 5}$ min \\
\hline Heart rate & $118.67 \pm 15.78$ & $119.82 \pm 15.89$ & $116.51 \pm 14.88$ & $118.50 \pm 15.68$ \\
\hline Systolic BP & $120.93 \pm 16.65$ & $125.33 \pm 17.01$ & $123.45 \pm 16.87$ & $124.50 \pm 16.98$ \\
\hline Diastolic BP & $72.40 \pm 8.26$ & $73.80 \pm 8.31$ & $72.90 \pm 8.30$ & $73.61 \pm 8.26$ \\
\hline Sp02 & $98.20 \pm 1.80$ & $98.90 \pm 1.83$ & $99.10 \pm 1.86$ & $99.42 \pm 1.86$ \\
\hline
\end{tabular}

\begin{tabular}{|c|c|c|c|c|}
\hline Group B & $\begin{array}{c}\text { Before Intubation } \\
\text { (mean) }\end{array}$ & $\mathbf{5 ~ m i n}$ & $\mathbf{1 0}$ min & $\mathbf{1 5}$ min \\
\hline Heart rate & $102.67 \pm 13.64$ & $101.47 \pm 13.01$ & $100.81 \pm 13.00$ & $101.70 \pm 13.76$ \\
\hline Systolic BP & $113.27 \pm 15.58$ & $115.27 \pm 16.21$ & $114.32 \pm 15.61$ & $113.65 \pm 15.28$ \\
\hline Diastolic BP & $74.13 \pm 9.01$ & $73.18 \pm 8.98$ & $74.15 \pm 8.89$ & $74.65 \pm 8.99$ \\
\hline Sp02 & $97.93 \pm 1.26$ & $99.47 \pm 1.99$ & $99.50 \pm 2.00$ & $99.48 \pm 1.99$ \\
\hline
\end{tabular}

There was not a significant change of haemodynamic profile in terms of heart rate and blood pressure after intubation in both the groups and when changes in heart rate with respect to the two groups were considered. A nonsignificant interaction $(\mathrm{p}=0.678)$ was seen, which reveals that the difference was statistically not significant and the pattern of change was similar in both the groups. Similarly, in terms of systolic and diastolic blood pressure, the pre and post-intubation changes (After $5 \mathrm{~min}$ ) are minimal in the two groups. When changes in systolic blood pressure with respect to two groups were considered a nonsignificant interaction $(p=0.575)$ was seen. Similarly, diastolic blood pressure $(p=0.552)$ nonsignificant interaction and $\mathrm{SpO}_{2} \quad(p=0.243)$ nonsignificant when compared between the two groups.

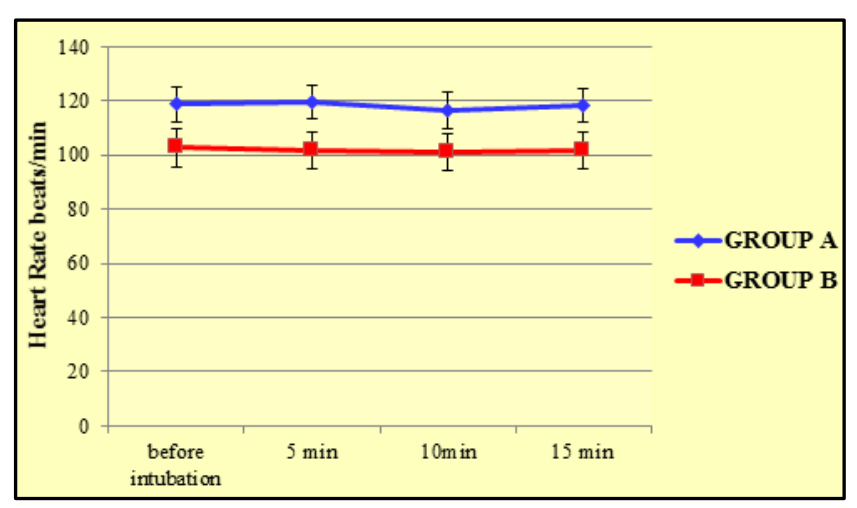



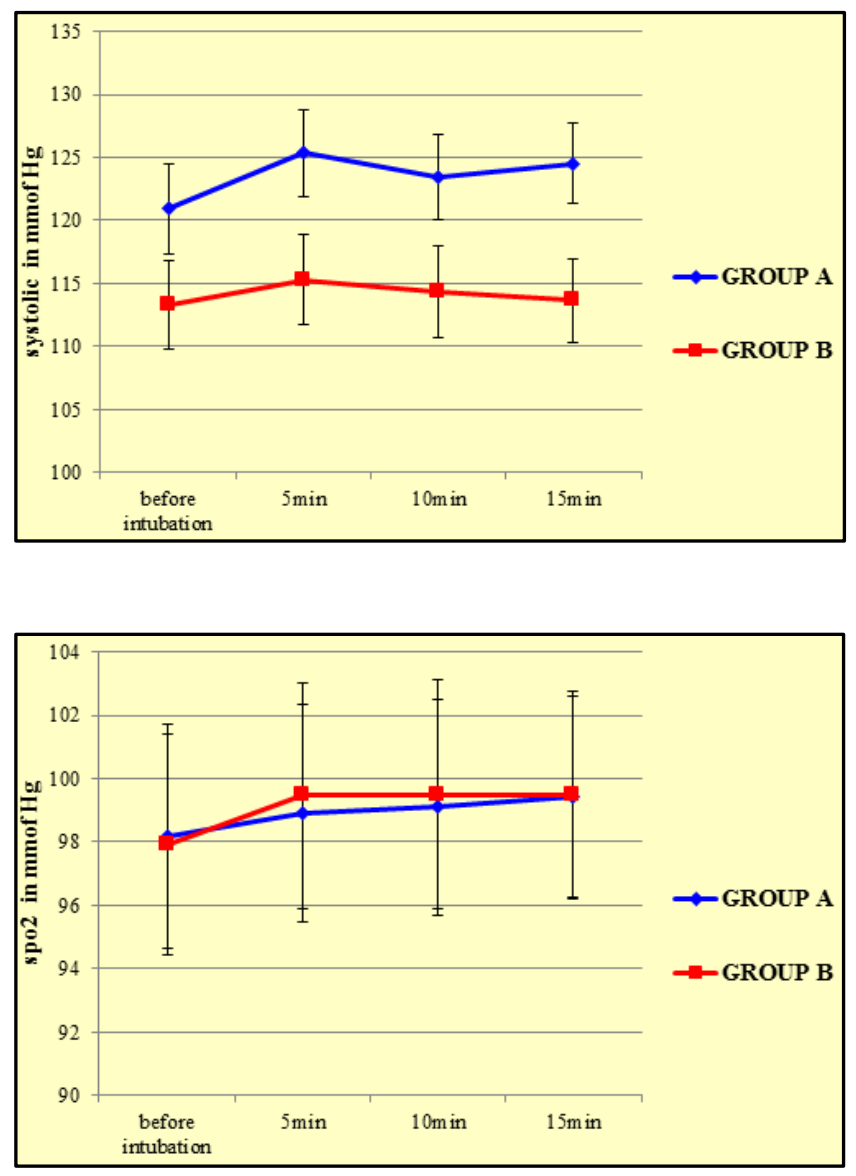

\section{DISCUSSION}

The present study was undertaken in an attempt to compare the haemodynamic effects of IV etomidate with IV propofol plus mephentermine as an induction of general anaesthesia in resuscitated patient of hypovolaemic shock. The study was conducted in two groups-Group A receiving inj. etomidate 0.3 $\mathrm{mg} / \mathrm{kg}$ IV as induction agent. Group B receiving 1\% inj. propofol $2 \mathrm{mg} / \mathrm{kg}$ IV with inj. mephentermine $6 \mathrm{mg} 5 \mathrm{mins}$ before administration of propofol.

Etomidate is a carboxylated imidazole-containing compound that is chemically unrelated to any other drug used for IV induction of anaesthesia. The imidazole nucleus renders etomidate like midazolam water soluble in acidic $\mathrm{pH}$ and lipid soluble at physiologic $\mathrm{pH}$ like midazolam. Its action is characterised by haemodynamic stability, minimal respiratory depression, and cerebral protective effects.

Its lack of effect on sympathetic nervous system, baroreceptor reflex regulatory system, and its effect of increased coronary perfusion even on patients with moderate cardiac dysfunction makes it an induction agent of choice in patients with cardiac disease. However, adverse effects such as pain on injection, thrombophlebitis, and myoclonus are some undesirable adverse effects.

In the present study, etomidate was well tolerated and no serious side effects or adverse reaction occurred in the study subjects. After the administration of induction dose of etomidate $0.3 \mathrm{mg} / \mathrm{kg}$ body wt., there was minimal changes in heart rate and the MAP was also well maintained in all the study subjects of Group A.

In various studies, etomidate has shown less cardiovascular depression and therefore minimise the use of vasopressor agent than other induction agent in sepsis and critically ill patients.3,4,5,6 Although, etomidate can cause

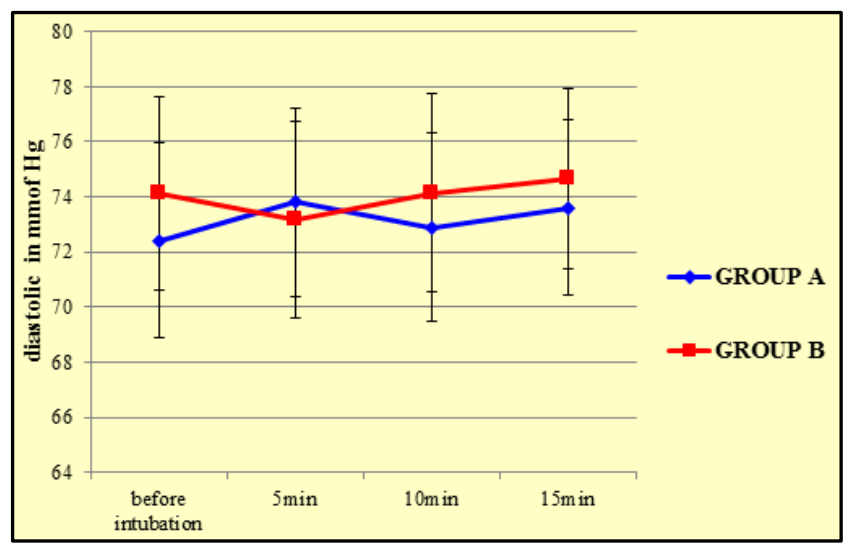

adrenal insufficiency in postoperative period, but clinical consequences of that is still unclear over its advantage to prevent hypotension (Cardioselective property) at induction.

Propofol, 2, 6-diisopropylphenol is most popular induction agent with its favourable characteristics of rapid, smooth induction and clear-headed recovery, decrease incidence of nausea and vomiting, etc. While on the other side, decrease in blood pressure, dose dependant depression of ventilation, and pain on injection are the major drawbacks.

Mephentermine sulphate, it is a cardiac stimulant indirectly acting sympathomimetic agent.

It belongs to the class of adrenergic and dopaminergic cardiac stimulants.

It acts by indirect stimulation of beta-adrenergic receptors causing the release of norepinephrine from its storage site. Mephentermine exhibits positive inotropic effect on myocardium, AV conduction, and refractory period of AV node is shortened with an increase in ventricular conduction velocity.

In the present study, the use of inj. propofol IV with inj. mephentermine in study Group B result in minimal fall in BP, adequate maintenance of cardiac output, heart rate, and MAP.

In a study conducted by Boysen et al, it was found there was no significant difference between two groups (Etomidate and propofol) as regard to apnoea following induction. The only negative characteristic noted with etomidate was high incidence of myoclonic jerks. ${ }^{7}$

In a study done by Geeta Karki et al comparing of haemodynamic characteristics of three induction agent etomidate, propofol, and thiopentone they found that on induction with etomidate there is no significant change in heart rate, systolic, diastolic, and mean arterial pressures. They also concluded that etomidate offers superior haemodynamic stability during induction compared to thiopentone and propofol. Thus, etomidate is a better induction agent for general anaesthesia. It can be the induction agent of choice in patients with comorbid cardiovascular illness in whom maintaining haemodynamic stability during induction is very crucial for a favourable outcome. ${ }^{8}$

In a case series reported by Alice et al in which they administered ketamine and propofol combination (Ketofol) for endotracheal intubations in critically ill patients and stated that the combination was associated with adequate sedation along with haemodynamic stability for up to 15 minutes following intubation. ${ }^{9}$

In our study, it was found that the incidence of side effects was minimal in both the groups, Group A (Receiving 
etomidate) and Group B (Receiving propofol with mephentermine) respectively.

\section{CONCLUSION}

As per result of our study for comparing haemodynamic effects between etomidate and propofol with mephentermine, we conclude that no significant difference is seen between study subjects of two groups (Group A and Group B) with regard to haemodynamic stability, side effects of drugs. We therefore suggest use of both etomidate and propofol with mephentermine as IV induction agent in resuscitated patient of hypovolaemic shock and the advantages of propofol can be beneficial for the patients.

\section{LIMITATION OF THE STUDY}

1. No. of study subjects were less.

2. Serum lactate level were not measured.

\section{REFERENCES}

1. Silverman A, Wang VJ. Shock: a common pathway for life threatening paediatric illnesses and injuries. Paediatric Emergency Medicine Practice 2005;2(10):1-22.

2. Gyton AC, Hall JE, et al. Circulatory shock and physiology of its treatment. Chapter 24. In: Textbook of Medical Physiology. 11 $1^{\text {th }}$ edn. Philadelphia, Pennsylvania: Elsevier Inc 2006:278-88.

3. $\mathrm{Xu}$ JS, Chen $\mathrm{HX}$, Chen $\mathrm{H}$, et al. Effect of etomidate on haemodynamics in elderly and shock patients during general anaesthesia induction. Di Yi Jun Yi Da Xue Xue Bao 2005;25(8):1060-1.
4. Aggarwal S, Goyal VK, Chaturvedi SK, et al. A comparative study between propofol and etomidate in patients under general anaesthesia. Brazilian Journal of Anaesthesiology 2016;66(3):237-41.

5. Hosseinzadeh H, Eidy M, Golzari SEJ, et al. Haemodynamic stability during induction of anaesthesia in elderly patients: propofol + ketamine versus propofol + etomidate. J Cardiovasc Thorac Res 2013;5(2):51-4.

6. Kaushal RP, Vatal A, Pathak R. Effect of etomidate and propofol induction on haemodynamic and endocrine response in patients undergoing coronary artery bypass grafting/mitral valve and aortic valve replacement surgery on cardiopulmonary bypass. Ann Card Anaesth 2015; 18(2):172-8.

7. Boysen K, Sanchez R, Krintel JJ, et al. Induction and recovery characteristics of propofol, thiopental, and etomidate. Acta Anaesthesiol Scand 1989;33(8):689-92.

8. Karki G, Singh V, Barnwal A, et al. A comparative evaluation of haemodynamic characteristics of the three induction agents - etomidate, thiopentone, and propofol. J. of Evolution of Med and Dent Sci 2014;3(34):9133-41.

9. De Moraes AG, Africano CJR, Hoskote SS, et al. Ketamine and propofol combination (Ketofol) for endotracheal intubations in critically ill patients: a case series. Am J Case Rep 2015;16:81-6. 